\title{
Sinergismo entre Ácidos orgânicos e Sorbato de potássio no controle de Aspergillusflavus
}

\author{
Bianca Rebonatto ${ }^{1}$, Janice Ruschel ${ }^{1}$, Naimara Vieira do Prado ${ }^{1}$, Elisa Yoko Hirooka ${ }^{2}$, \\ Alessandra Machado-Lunkes ${ }^{1}$ e Elisabete Hiromi Hashimoto ${ }^{3}$
}

O controle de fungos na produção de grãos requer estratégias em toda a cadeia produtiva, para prevenir a contaminação por micotoxinas. A substituição de fungicidas químicos por ácidos orgânicos (geralmente reconhecidos como seguro) desponta como uma perspectiva interessante. A pesquisa teve como objetivo determinar concentração inibitória mínima (CIM) de ácidos orgânicos, sorbato de potássio e respectivas combinações no controle de Aspergillusflavus NRRL 3251 produtor de aflatoxina $\mathrm{B}_{1}, \mathrm{~B}_{2}$ e $\mathrm{M}_{1}$. $\mathrm{O}$ inóculo de 104 esporos. $\mathrm{mL}^{-1}$ foi calculado baseado na contaminação usual no milho e em ração animal. As melhores CIM in vitro foram: combinação de ácido acético (AA 83,26 mM) + propiônico (AP 6,74 $\mathrm{mM})$; AA $(8,32 \mathrm{mM})+$ sorbato de potássio $(\mathrm{SP} 13,31 \mathrm{mM})$ e AP $(6,74 \mathrm{mM})+\mathrm{SP}(33,28 \mathrm{mM})$. Considerando a dose comercialmente utilizada de ácido propiônico 0,5\%, a combinação do ácido propiônico com sorbato de potássio e ácido acético poderia reduzir respectivamente cerca de 24,63 e $70,19 \%$ o custo em conservante.

Palavras-chave:Conservante. Fungo. Ácido fraco. Antifúngico.Inibição.Sinergia.

\section{Synergism between Organic acids and Potassium sorbate in the Aspergillusflavus control}

The control of fungi in grain production requires strategies to prevent the contamination by mycotoxins. The replacement of chemical fungicides with organic acids (Generally Recognized as Safe) emerges as an interesting perspective. This work aimed to determine the minimum inhibitory concentration (MIC) of organic acids, potassium sorbate and their combinations to control Aspergillusflavus NRRL 3251, aflatoxin $\mathrm{B}_{1}, \mathrm{~B}_{2}$ and $\mathrm{M}_{1}$ producer. The inoculum of 104 spores.mL ${ }^{-1}$ was calculated based on the commonly contamination in maize and animal feed. The best MICs in vitro were: acetic acid (AA $83.26 \mathrm{mM})+$ propionic acid combination $(\mathrm{PA} 6.74 \mathrm{mM}) ; \mathrm{AA}(8.32 \mathrm{mM})+$ potassium sorbate (PS $13.31 \mathrm{mM})$ and PA $(6.74 \mathrm{mM})+$ PS $(33.28 \mathrm{mM})$. Considering the commercial used dose of propionic acid $0.5 \%$ in animal feed, the combination of propionic acid with potassium sorbate and acetic acid could reduce the cost with preservative of 24.63 and $70.19 \%$, respectively

Keywords:Preservative. Fungus. Weak acid. Antifungal. Inhibition. Synergy.

${ }^{1}$ Universidade Tecnológica Federal do Paraná - Câmpus Francisco Beltrão, Caixa Postal 135, CEP 85601-050 Francisco Beltrão -PR.

${ }^{2}$ Universidade Estadual de Londrina. Departamento de Ciência e Tecnologia de Alimentos, Centro de Ciências Agrárias.

${ }^{3}$ Universidade Tecnológica Federal do Paraná - Câmpus Francisco Beltrão. Endereço para correspondência: Caixa Postal 135, CEP 85601-050 Francisco Beltrão -PR. E-mail:

elisabete@utfpr.edu.br. 


\section{INTRODUÇÃO}

No mundo todo, grandes quantidades de alimento e ração são perdidas devido à deterioração por fungos ${ }^{[1]}$. As matérias-primas de origem vegetal utilizadas na fabricação de rações são susceptíveis à contaminação fúngica desde o campo, armazenamento, até seu processamento. Entre os contaminantes, destaca-se o Aspergillusflavus, um fungo que pode se desenvolver durante a armazenagem e produtor de aflatoxina(AF). A AF é apontada como toxina natural de maior toxicidade com caráter cumulativo na cadeia alimentar, causando perigo à saúde humana e animal ${ }^{[2]}$.

A aplicação de calor na conservação de alimentos é a base do processamento térmico. A fervura, cozimento, fritura e extrusão podem eliminar microrganismos viáveis, no entanto não são capazes de eliminar completamente as micotoxinas ${ }^{[3]}$. Devido a termo resistência, o controle de aflatoxina deve ser abordado desde o início de desenvolvimento fúngico.

Neste sentido, a substituição de fungicida químico de elevada toxicidade pela tecnologia preventiva vem sendo assunto imprescindível. As perspectivas despontam em conservantes comuns baseados em ácido orgânico, classificado entre 'Geralmente Reconhecidos Como Seguro' (GRAS), tais como: ácido lático, acético, propiônico e sorbato de potássio ${ }^{[4,5,6,7]}$.

O uso crescente de conservante baseado em ácido orgânico no setor industrial se deve à simplicidade, rapidez, eficiência e baixo custo capaz de garantir a qualidade e vida de prateleira ${ }^{[8]}$. Embora difundido, o emprego ainda se mantém restrito a determinados compostos, se comparado ao vasto número de compostos antimicrobianos disponíveis, gerando dúvidas na escolha ${ }^{[9]}$.

A eficiência dos ácidos orgânicos depende da constante de dissociação, atividade de água, $\mathrm{pH}$, temperatura de armazenamento, entre outros ${ }^{[10,11]}$. Considerando a possibilidade de ação combinada no efeito sinérgico, o trabalho tem como objetivo avaliar diferentes combinações de ácido orgânico e sorbato de potássio no controle de $A$. flavus micotoxigênico, visando a aplicação destes como conservante em ração animal.

\section{MATERIAL E MÉTODOS}

\section{Amostras de milho e ração}

Para se definir a concentração do inóculo de Aspergillusflavus NRRL3251 utilizado nos testes in vitro foi realizada a análise $\mathrm{da}$ contaminação fúngica de milho e ração de uma indústria processadora local. A contagem de bolores e leveduras foi avaliada em milho (30 amostras) e ração peletizada (30 amostras). As amostras foram coletadas no período de junho a agosto de 2016 na região Centro-Sul do Estado do Paraná. As amostras de ração corresponderam ao mesmo lote de milho destinado ao processamento. A contagem total de bolores e leveduras foi realizada conforme Silva et al. ${ }^{[12]}$.

As amostras de milho e ração também foram analisadas quanto a contaminação por aflatoxina. A extração foi realizada em coluna de imunoafinidade - Aflatest ${ }^{\circledR}{ }^{[13]} \mathrm{e}$ AFB1 quantificada por cromatografia líquida de alta eficiência acoplado ao espectrofotômetro de massas tipo triplo quadrupolo - UPLC (Acquity UPLC-MS/MS, modelo Xevo TDQ Waters). Os extratos foram aplicados em coluna C18 (Acquity UPLC BEH; 1,7 $\mu \mathrm{m}, 2,1 \mathrm{~mm}$ d.i. x 100 $\mathrm{mm}$ ). A fase móvel consistiu de fase móvel A $\mathrm{H} 2 \mathrm{O}+0,1 \%$ Ácido fórmico e Fase móvel B (Acetonitrila $+0,1 \%$ Ácido fórmico). A metodologia foi desenvolvida utilizando padrão de aflatoxina (Sigma-Aldrich, Sant Louis, Missouri, EUA), sendo o limite de detecção de $2 \mu \mathrm{g} \cdot \mathrm{kg}^{-1} \mathrm{de}$ AFB1. 
Tabela 1 - Concentrações testadas dos antifúngicos para determinação da concentração inibitória mínima (CIM)

\begin{tabular}{|c|c|c|}
\hline Composto & Características do produto & Concentrações \% (mM) \\
\hline Ácido Acético & $\begin{array}{c}\mathrm{CH}_{3} \mathrm{COOH} \\
\text { MM: } 60,05 \mathrm{~g} / \mathrm{mol} \\
\text { Princípio Ativo: } 97,70 \% \text {, } \\
\text { pKa: } 4,75\end{array}$ & $\begin{array}{c}0,05(8,32) ; 0,1(16,65) \\
0,2(33,30) ; 0,5(83,26) \\
\text { e } 0,8(133,22)\end{array}$ \\
\hline Ácido Lático & $\begin{array}{c}\mathrm{C}_{3} \mathrm{H}_{6} \mathrm{O}_{3} \\
\text { MM: 90,08 g/mol } \\
\text { Princípio Ativo: } 71,35 \% \\
\text { pKa: 3,88 }\end{array}$ & $\begin{array}{c}0,05(5,55) ; 0,1(11,01) ; \\
0,2(22,20) ; 0,5(55,50) ; \\
0,8(88,80) ; 1,2(133,21) ; \\
1,5(166,51) ; 1,8(199,82) \\
\text { e } 2,0(222,02)\end{array}$ \\
\hline Ácido Propiônico & $\begin{array}{c}\mathrm{C}_{3} \mathrm{H}_{6} \mathrm{O}_{2} \\
\text { MM: } 74,08 \mathrm{~g} / \mathrm{mol} \\
\text { Princípio Ativo: } 97,12 \% \\
\text { pKa: } 4,88\end{array}$ & $\begin{array}{l}0,05(6,74) ; 0,1(13,49) \\
0,2(26,99) ; 0,5(67,49) \\
\text { e } 0,8(107,99)\end{array}$ \\
\hline $\begin{array}{c}\text { Sorbato de } \\
\text { Potássio }\end{array}$ & $\begin{array}{c}\mathrm{C}_{6} \mathrm{H}_{7} \mathrm{KO}_{2} \\
\text { MM: } 150,22 \mathrm{~g} / \mathrm{mol} \\
\text { Princípio Ativo:98,00 \%, } \\
\text { pKa: 4,76 (ácido sórbico) }\end{array}$ & $\begin{array}{l}0,05(3,32) ; 0,1(6,65) ; \\
0,2(13,31) ; 0,5(33,28) ; \\
0,8(53,25) ; 1,2(79,88) ; \\
1,5(99,85) ; 1,8(119,82) \\
\quad \text { e } 2,0(133,13)\end{array}$ \\
\hline
\end{tabular}

Para determinação da concentração inibitória mínima (CIM) foram testados os ácidos propriônico, acético e lático e sorbato de potássio. As concentrações dos compostos testados estão apresentadas na Tabela 1 .

As concentrações testadas foram preparadas em água destilada estéril. O preparo das soluções testes levou em consideração a pureza do princípio ativo presente no rótulo, e confirmação através de titulações dos ácidos para a correção do percentual real de cada reagente. As concentrações testadas para determinação da CIM basearam-se nos valores sugeridos em literatura, e além destas, foram testadas concentrações superiores e inferiores às recomendadas. $\mathrm{O}$ inoculo consistiu de 104 esporos. $\mathrm{mL}^{-1} \mathrm{de}$ Aspergillusflavus NRRL 3251 semeado por técnica de Pourplate $(1 \mathrm{~mL})$ e Spread plate $(100 \mu \mathrm{L})$ empregando-se $19 \mathrm{~mL}$ de batata dextrose Agar (BDA) adicionado de cada agente antifúngico.

Os ácidos acético, propiônico, lático ou sorbato de potássio foram avaliados individualmente e combinados. A Tabela 2 apresenta as combinações dos compostos testados e suas concentrações. As concentrações foram determinadas com base nos resultados obtidos na determinação da CIM dos compostos testados individualmente $\mathrm{e}$ também em testes prévios realizados. Para as combinações do ácido acético com sorbato de potássio e ácido propiônico com sorbato de potássio, foram incluídos tratamentos adicionais, baseado em resultados prévios da CIM de cada agente. As combinações foram realizadas através de delineamento composto central rotacional (DCCR), com 3 repetições no ponto central utilizando o software XLSTAT, versão 2017. 
Tabela 2 - Concentrações dos compostos antifúngicos em testes combinados dois a dois

\begin{tabular}{|c|c|c|c|c|c|c|c|c|c|c|c|}
\hline \multicolumn{12}{|c|}{ Concentração (\%) } \\
\hline $\mathbf{A A}$ & $\mathbf{A P}$ & $\mathbf{A A}$ & SP & $\mathrm{AL}$ & SP & $\mathbf{A A}$ & $\mathbf{A L}$ & $\mathbf{A L}$ & AP & $\mathbf{A P}$ & SP \\
\hline 0,025 & 0,025 & 0,025 & 0,25 & 0,40 & 0,40 & 0,025 & 0,40 & 0,40 & 0,025 & 0,025 & 0,40 \\
\hline 0,250 & 0,025 & 0,250 & 0,25 & 1,00 & 0,40 & 0,250 & 0,40 & 1,00 & 0,025 & 0,10 & 0,40 \\
\hline 0,025 & 0,10 & 0,025 & 1,00 & 0,40 & 1,00 & 0,025 & 1,00 & 0,40 & 0,10 & 0,025 & 1,00 \\
\hline 0,250 & 0,10 & 0,250 & 1,00 & 1,00 & 1,00 & 0,250 & 1,00 & 1,00 & 0,10 & 0,10 & 1,00 \\
\hline 0,137 & 0,062 & 0,137 & 0,625 & 0,70 & 0,70 & 0,137 & 0,70 & 0,70 & 0,062 & 0,062 & 0,70 \\
\hline \multicolumn{2}{|c|}{ Adicionais } & $\begin{array}{l}0,250 \\
0,025\end{array}$ & $\begin{array}{l}0,10 \\
0,10\end{array}$ & & & & & & & $\begin{array}{l}0,10 \\
0,025 \\
0,025 \\
0,10\end{array}$ & $\begin{array}{l}0,10 \\
0,250 \\
0,10 \\
0,250\end{array}$ \\
\hline
\end{tabular}

AA: ácido acético; AP: ácido propiônico, AL: ácido lático; SP: sorbato de potássio

As placas foram incubadas a $25^{\circ} \mathrm{C}$ por 7 dias (estufa BOD, SL-200/364, Solab) e o resultado expresso em Unidades Formadoras de Colônias (UFC). Após a determinação de CIM individual de cada agente, foram testadas as combinações dos agentes em pares. $\mathrm{O}$ pH do meio após a adição do ácido e antes do inóculo foi determinado em pHmetro (F20-KIT, Mettler Toledo) de acordo com os procedimentos descritos pelo Instituto Adolfo Lutz $^{[14]}$. O índice da concentração fracionária inibitória (ICFI) foi determinado conforme descrito por Odds ${ }^{[15]}$ :

$$
\mathrm{ICFI}=\Sigma \mathrm{FIC}=\mathrm{FIC}_{\mathrm{A} 1}+\mathrm{FIC}_{\mathrm{A}} 2=\underset{w_{\underline{A} 1}}{\mathrm{CIM}_{\mathrm{A} 1}}+\frac{\underline{\mathrm{C}}_{\underline{\mathrm{A}} 2}}{\mathrm{CIM}_{\mathrm{A} 2}}
$$

Onde: $\mathrm{C}_{\mathrm{A} 1}$ e $\mathrm{C}_{\mathrm{A} 2}=$ menor concentração da combinação dos agentes A1 e A2 com atividade antimicrobiana; $\mathrm{CIM}_{\mathrm{A} 1}$ e $\mathrm{CIM}_{\mathrm{A} 2}=$ CIM de agentes A1 e A2 separadamente. A interação entre os agentes combinados foi analisada, considerando: FICI $\leq 0,5$ efeito sinérgico; $0,5<$ FICI $<4$ indiferente; e FICI $\geq$ 4 antagonismo $^{[15]}$.

\section{RESULTADOS E DISCUSSÃO}

A Tabela 3 apresenta o nível de contaminação de $A$. flavus em relação à contagem de bolores e leveduras em milho e ração peletizada. As amostras de milho apresentaram contagem de $A$. flavus atingindo 4,7 Log UFC. $\mathrm{g}^{-1} \mathrm{e}$ em ração a contagem máxima foi de 3,3 Log UFC.g-1. Considerando o tratamento térmico durante a peletização que pode variar de $70-115 \mathrm{oC}^{[16]}$ e que o milho representa em torno de $40 \%$ da formulação da ração, uma redução da contagem microbiana já era esperada no produto final ${ }^{[17]}$.

Tabela 3 - Contagem total de bolores e leveduras em amostras de milho e ração peletizada.

\begin{tabular}{cccccc}
\hline $\begin{array}{c}\text { Contagem } \\
(\text { Log UFC.g-1) }\end{array}$ & \multicolumn{3}{c}{ Amostras contaminadas (N) } \\
\hline & \multicolumn{2}{c}{$\begin{array}{c}\text { Aspergillusflav } \\
\text { us }\end{array}$} & & \multicolumn{2}{c}{$\begin{array}{c}\text { Bolores e } \\
\text { leveduras }\end{array}$} \\
\cline { 2 - 3 } \cline { 5 - 6 } & Milho & Ração & & Milho & Ração \\
\hline n.d.-2 & 24 & 29 & & - & 23 \\
$3-3,9$ & 4 & 1 & & 13 & 6 \\
$4-4,7$ & 2 & 0 & & 17 & 1 \\
\hline
\end{tabular}

$\mathrm{N}=60$, sendo: milho $\mathrm{n}=30$, ração $\mathrm{n}=30$.

O tratamento térmico exercido durante a peletização da ração auxilia na redução dos níveis de contaminação fúngica e de micotoxinas. A diminuição irá depender de alguns fatores como temperatura, tempo de condicionamento, umidade e nível de 
contaminação ${ }^{[17]}$. As aflatoxinas resistem altas temperaturas, requerendo faixas de 267 a 306 ${ }^{\circ} \mathrm{C}$ para sua inativação, temperaturas muitas vezes inviáveis ao processamento de alimentos $^{[18]}$. Milaneet al $(2014)^{[19]}$ avaliaram o efeito do processamento térmico para redução dos níveis de contaminação inicial de aflatoxinas (71,3 $\mu \mathrm{g} \cdot \mathrm{kg}-1)$ em amostras de milho, e através da peletização $82{ }^{\circ} \mathrm{C}$ por 60 segundos. Após a peletização, os níveis de aflatoxinas foram reduzidos em $78 \%$ na ração final em relação à contaminação inicial.

Embora a aflatoxina seja considerada termo resistente, a $\mathrm{AFB}_{1}$ não foi detectada em nenhuma amostra de ração. $\mathrm{E}$ somente 3 amostras de milho apresentaram contaminação por $\mathrm{AFB}_{1}$ em níveis de 2 a $15 \mu \mathrm{g} . \mathrm{kg}-1$. Embora tenha sido analisada somente o análogo $\mathrm{AFB}_{1}$, em 59 amostras analisadas (98,3\%), os níveis detectados foram inferiores aos limites máximos estabelecidos pela legislação nacional de $20 \mu \mathrm{g} \cdot \mathrm{kg}^{-1} \mathrm{e}$ internacional de $10 \mu \mathrm{g} \cdot \mathrm{kg}^{-1}$ para aflatoxinas $\left(B_{1}+B_{2}+G_{1}+G_{2}\right)^{[20,21]}$. Os resultados indicam boa qualidade da matéria prima. Outrossim, salienta-se a importância do controle de armazenamento pós-processamento térmico, visto que o produto pode sofrer contaminação posterior ${ }^{[22]}$.

Além de apresentar os resultados da contaminação de milho e ração na indústria, os dados da Tabela 1, forneceu parâmetros para o teste in vitro. Baseado na contagem máxima de colônias de $A$. flavus ( 4 Log UFC.g-1) nas amostras analisadas (Tabela 3), foi definido a concentração de 104 esporos.mL $L^{-1}$ para o inóculofúngico nos testes in vitro.

A Tabela 4 apresenta as concentrações inibitórias mínimas (CIM) dos compostos testados e o pH do meio de cultura na CIM frente ao A. flavus NRRL 3251.
Tabela 4 - Concentração inibitória mínima (CIM) de ácidos antimicrobianos contra $A$. flavus NRRL 3251 e $\mathrm{pH}$.

\begin{tabular}{ccc}
\hline $\begin{array}{c}\text { Acido orgânico } \\
(\mathbf{p K a})\end{array}$ & $\mathbf{C I M} \% \mathbf{( m M )}$ & $\mathbf{p H}$ \\
\hline Ácido acético & $0,5(83,26)$ & $4,14 \pm 0,020$ \\
$\quad(4,75)$ & & \\
Ácido propiônico & $0,2(26,99)$ & $4,59 \pm 0,010$ \\
$\quad(4,88)$ & & \\
Ácido lático $(3,88)$ & $>2,0(222,02)$ & $3,35 \pm 0,009$ \\
$\quad$ Sorbato de & $2,0(133,13)$ & $7,04 \pm 0,008$ \\
potássio $(4,76) \#$ & & \\
\hline
\end{tabular}

Inóculo de $A$. flavus NRRL 3251: $10^{4}$ esporos. $\mathrm{mL}^{-1}$. \# pKa referente ao ácido sórbico.

Os compostos antimicrobianos em alimentos e ração são aplicados industrialmente misturados na matriz alimentar. Mas há de considerar que a contaminação fúngica pode se dar por matéria prima contaminada ou por recontaminação após o processamento. Para avaliar estas condições foram testadas duas técnicas de inoculação: $1 \mathrm{~mL}$ em profundidade misturados ao meio de cultura (Pourplate) e 100 $\mu \mathrm{l}$ na superfície do ágar BDA (Spread plate). As concentrações inibitórias mínimas (CIM) dos compostos testados (Tabela 4) foram as mesmas independente da técnica de inoculação.

Entre os ácidos testados, o ácido propiônico $(\mathrm{pKa}=4,88)$ apresentou menor CIM contra A. flavus NRRL 3251 (26,99 Mm) com valor de $\mathrm{pH} 4,59$, um pouco abaixo de seu pKa. O valor de CIM para o ácido acético (de pKa 4,75) foi de 0,5\% (83,26Mm) no $\mathrm{pH} 4,14$. $\mathrm{O}$ ácido lático ( $\mathrm{pKa} 3,88$ ) não apresentou atividade inibitória mesmo na maior concentração testada (222,02 mM, pH 3,35) (Tabela 4).

A capacidade de inibição dos ácidos é relacionada ao valor do $\mathrm{pH}$ do meio que deve ser menor que o pKa do ácido em questão, pois a ação antimicrobiana é atribuída a forma não dissociada do ácido ${ }^{[23]}$. 
Devido a baixa solubilidade do ácido sórbico de $0,25 \mathrm{~g}$ em $100 \mathrm{~mL}$ de água a $30{ }^{\circ} \mathrm{C}^{[24]}$, neste experimento foi testado o seu sal, sorbato de potássio que apresenta solubilidade 58,2 $\mathrm{g} / 100 \mathrm{~mL}$ de água à $25{ }^{\circ} \mathrm{C}^{[25]}$. A CIM do sal de sorbato para inibir a cepa NRRL 3251 foi de $113,13 \mathrm{mM}$ (2,0\%). Considerando o pKa do ácido sórbico, 4,76, o pH 7,04 do meio BDA (Tabela 4) interferiu diretamente na ação do sorbato de potássio, que se manteve dissociado. Em um experimento utilizando massa de pão acidificada com ácido cítrico ( $\mathrm{pH} 4,5)$, este ácido favoreceu a protonação do sal. Nestas condições $0,3 \%$ do sorbato de potássio foram suficientes para controle de $10^{6}$ esporos. $\mathrm{mL}^{-1} \mathrm{de}$ Aspergillus sp. na massa de $\mathrm{pão}^{[26]}$.

A avaliação da contaminação fúngica no alimento que se pretende aplicar determinado agente antimicrobiano é importante para determinação da CIM. Além disso, os testes in vitro, deve simular também a forma de aplicação pretendida do composto. Dependendo da concentração do inóculo e forma de aplicação diferentes concentrações de CIM são relatadas para controle de $A$. flavus.Pelaezet al. (2012) ${ }^{[27]}$ avaliaram de $A$. flavustoxigênicas e não toxigênicasa CIM apresentada pelo ácido acético variou de 38,1 mM (pH 4,69) a 41,6 $\mathrm{mM}$ ( $\mathrm{pH} 4,62)$, sendo as cepas toxigênicas mais sensíveis ${ }^{[27]}$. O maior valor, ou seja, a CIM para cepas não toxigênicas correspondeu a metade da CIM apresentada para controle de A. flavus NRRL3251 (83,26 mM, Tabela 2). No entanto Peláezet al. ${ }^{[27]}$ inocularam 102 esporos por placa $\left(10 \mu \mathrm{L}\right.$ de 104 UFC.mL $\left.{ }^{-1}\right)$, menor número (103 ) de esporos que a cepa NRRL $3251(100 \mu \mathrm{L}$ de $10^{4}$ esporos. $\mathrm{mL}^{-1}$ ) sendo necessário então uma concentração maior de ácido acético para inibir seu crescimento (Tabela 4). Por outro lado, em suporte sólido (disco de papel) o inóculo de 5,0 x $10^{5}$ UFC.mL1 de $A$. flavus foi inibido com 0,35\% (57,85 mM) de ácido acético ${ }^{[28]}$.

O ácido lático um ácido fraco de cadeia curta (CH3-CHOH-COOH) é considerado um eficiente antimicrobiano, sendo sua ação mais relatada para o controle de bactérias ${ }^{[29]}$. O controle de bolores por sua vez, requer concentrações mais elevadas de ácido lático. Concentrações de 405,4 mM em pH 2,69 foi necessária para inibir cepa toxigência de $A$. flavus AFUNL1 ${ }^{[27]}$, ou seja, o dobro da maior concentração testada frente à cepa NRRL 3251 (Tabela 4), sendo esta resistente a 222,2 $\mathrm{mM}$ de ácido lático. Os dados indicam que para a atividade antifúngica é necessário que o ácido esteja predominantemente na sua forma não ionizada.

Um estudo sobre o efeito do $\mathrm{pH}$ na determinação CIM dos ácidos propiônico, acético e lático demostrou uma maior efetividade destes ácidos em $\mathrm{pH}$ 3,0 quando comparado à $\mathrm{pH}$ 5,0 e 7,0 para controle de bolores. Em pH 7, todos os ácidos requereram concentrações $\geq 500 \mathrm{mM}$ para a inibição das cepas Aspergillusfumigatus J9 e A. nidulans J283. Em pH 5,0 os valores de CIM para ácido propiônico e acético foram 50 e $80 \mathrm{mM}$, respectivamente, e acima de $500 \mathrm{mM}$ para ácido lático. Em pH 3, os valores de CIM foram de $\leq$ $20 \mathrm{mM}$ para ácido propiônico e acético, e $\geq 200$ $\mathrm{mM}$ para o ácido lático ${ }^{[30]}$. Os resultados atestam a importância da forma não dissociada na ação antimicrobiana de ácidos orgânicos.

Outros mecanismos de ação dos ácidos orgânicos podem ser em decorrência do estresse oxidativo e perturbação na membrana plasmática $^{[31,32]}$. Os ácidos fracos podem inibir a glicólise, uma vez que uma enzima chave da glicólise, a fosfofrutoquinase é sensível a valores baixos de $\mathrm{pH}^{[33]}$. A análise da atividade enzimática de A. niger, sugere uma redução substancial na atividade enzimática à medida que o $\mathrm{pH}$ reduz para valores inferiores a 6,0 as enzimas mais sensíveis ao $\mathrm{pH}$ são a hexoquinase e a fosfofrutoquinase ${ }^{[34]}$.

A interação de ácidos orgânicos pode apresentar um efeito sinérgico, tornando a membrana das células mais permeáveis a outros ácidos. A sinergia é detectada quando a 
combinação de dois compostos é mais eficaz do que o composto sozinho, quando a inibição é superior a individual ou quando ocorre uma redução de 1 Log em comparação ao composto sozinho ${ }^{[35,36,37]}$. Uma medida para avaliar a sinergia é a determinação do índice da concentração fracionária inibitória (ICFI), que calculado a partir da CIM dos agentes isolados e combinados $^{[15]}$. A Tabela 5 apresenta a CIM, $\mathrm{pH}$ e os valores do ICFI dos ácidos combinados sobre A. flavus NRRL 3251.

Tabela 5 - Concentração inibitória mínima (CIM) e índice da concentração fracionária inibitória (ICFI) para controle de $A$. flavus NRRL 3251 e $\mathrm{pH}$.

\begin{tabular}{lccc}
\hline \multicolumn{1}{c}{ Ácido combinado $(\mathbf{m M})$} & CIM \% & pH & ICFI \\
\hline AA $(41,63)+$ AP $(3,37)$ & $0,25+0,025$ & $4,29 \pm 0,005$ & 0,62 \\
AA $(4,16)+$ SP $(6,65)$ & $0,025+0,1$ & $5,45 \pm 0,010$ & 0,09 \\
AL $(44,40)+$ SP $(26,62)$ & $0,4+0,4$ & $4,22 \pm 0,020$ & - \\
AA $(41,63)+$ AL $(44,40)$ & $0,25+0,4$ & $3,81 \pm 0,010$ & - \\
AL $(44,40)+$ AP $(13,49)$ & $0,4+0,1$ & $3,81 \pm 0,010$ & - \\
AP $(3,37)+$ SP $(16,64)$ & $0,025+0,25$ & $5,81 \pm 0,010$ & 0,25 \\
\hline I
\end{tabular}

Inóculo de $A$. flavus NRRL 3251: $10^{4}$ esporos. $\mathrm{mL}^{-1}$.

AA: ácido acético (pKa:4,75); AP.: ácido propiônico (pKa: 4,88), AL: ácido lático (pKa: 3,88); SP: sorbato de potássio (pKa: 4,76 ácido sórbico).

Os valores de ICFI indicaram que o efeito sinérgico $(\mathrm{IFCI}<0,5)$ foi detectado na combinação de sorbato de potássio com ácido acético (ICFI $=0,09, \mathrm{pH} 5,45)$ e com ácido propiônico $\quad(\mathrm{ICFI}=0,25, \quad \mathrm{pH} \quad 5,81)$. Isoladamente o sorbato de potássio apresentou CIM (133,13 mM) em pH 7,04 (Tabela 2), mas a sua ação antifúngica é mais efetiva se aplicado em condições ácidas ${ }^{[26]}$. Quando combinado o sorbato de potássio apresentou atividade em $\mathrm{pH}$ que variou de 4,22 a 5,81 em concentrações de 6,25 a 26,62 mM, para ácido acético e lático, respectivamente (Tabela 5).

Em condições ácidas há o predomínio do ácido sórbico ( $\mathrm{pKa}$ 4,76), indicando a contribuição direta do ácido lático para este efeito. Considerado o ácido mais forte entre os testados (pka 3,88), o ácido lático não apresentou atividade antifúngica isoladamente (Tabela 4), mas foi capaz, quando combinado de inibir o $A$. flavus NRRL 3251 na concentração de 44,40 mM, contribuindo para ação dos sorbato de potássio e demais ácidos.

O $\mathrm{pH}$ do citoplasma é considerado neutro, assim o ácido sórbico ( $\mathrm{pKa} 4,76$ ), além de reduzir o pH intracelular, exerce ação no metabolismo $^{[32]}$. As enzimas sulfidrílicasfumarase, aspartase e succinatodesidrogenase são inibidas pelo ácido sórbico, impedindo a assimilação oxidativa da glicose, acetato, succinato e fumarato ${ }^{[38]}$.

A permeabilidade na membrana depende da lipofilicidade do composto e contribui para a ação antimicrobiana. A concentração do ácido propiônico combinado com ácido lático $(13,49 \mathrm{mM})$ e acético $(3,37$ $\mathrm{mM}$ ) foi, respectivamente duas e oito vezes inferior (Tabela 5), quando comparado com a sua CIM isoladamente (26,99 $\mathrm{mM}$, Tabela 4). Considerando os coeficientes de partição (Log $\mathrm{P})$, entre os ácidos testados, o ácido propiônico é o mais lipofílico $\log \mathrm{P}=0,33$, já os ácidos lático $(\log \mathrm{P}=-0,72)$ e acético $(\log \mathrm{P}=-0,17)$ são considerados hidrofílicos ${ }^{[39]}$. Assim a combinação com o ácido lático e acético contribuiu para a forma não ionizada do ácido propiônico e favorecendo a sua permeabilidade na membrana.

A principal atividade dos ácidos é atribuída às moléculas não dissociadas, que ocorre em valores de $\mathrm{pH}$ baixos. O predomínio da forma não dissociada de ácidos lipofílicos favorece a sua permeabilidade na membrana 
plasmática por difusão. No citoplasma, com o $\mathrm{pH}$ próximo a 7,0 as moléculas de ácido são dissociadas se acumulam dentro da célula, diminuindo o $\mathrm{pHi} \quad(\mathrm{pH}$ intracelular), acidificando-o e inibindo o metabolismo, especialmente as enzimas glicolíticas ${ }^{[32,40]}$. A interferência no metabolismo provocadas por ácidos orgânicos, reduz da taxa de crescimento e estende a fase de declínio microbiano ${ }^{[27,41]}$.

Com os resultados obtidos in vitro é possível propor a indústria testes in loco, em concentrações mais baixas de ácidos orgânicos em relação às concentrações recomendadas pelos fornecedores de agente antifúngico comercial. Exemplificando, atualmente é recomendado para rações melaçadas, o uso de ácido propiônico na concentração de $0,5 \%$ $(67,49 \mathrm{mM})$ no melaço. Considerando o preço destes agentes, o ácido acético (80\%) é o de menor custo (US\$1,43 / kg), seguido do ácido propiônico (US\$3,51 / kg, 65\%), ácido lático (US\$ 5,68/kg, 85\%) e sorbato de potássio (US\$ 7,45 / kg, 98\%). Considerando o valor do ácido propiônico comumente utilizado pelas indústrias, calculou-se o custo relativo das combinações (Tabela 6)

Tabela 6 - Custo relativo da combinação entre ácidos orgânicos e sorbato de potássio em relação ao ácido propiônico comercial.

\begin{tabular}{ccc}
\hline $\begin{array}{c}\text { Compostos comerciais } \\
\text { (US\$.kg-1) }\end{array}$ & $\begin{array}{c}\text { Concentração } \\
\mathbf{( \% )}\end{array}$ & $\begin{array}{c}\text { Custo relativo** } \\
\text { (\%) }\end{array}$ \\
\hline AP comercial $\mathbf{( 5 , 4 0 )}$ & $\mathbf{0 , 5}$ & $-78,42$ \\
\hline AA $(1,79)+$ AP $(5,40)$ & $0,25+0,025$ & $-70,19$ \\
AA $(1,79)+$ SP $(7,60)$ & $0,025+0,1$ & $+111,55$ \\
AL $(6,68)+$ SP $(7,60)$ & $0,4+0,4$ & $-1,03$ \\
AA $(1,79)+$ AL $(6,68)$ & $0,25+0,4$ & $+18,96$ \\
AL $(6,68)+$ AP $(5,40)$ & $0,4+0,1$ & $-24,63$ \\
AP $(5,40)+$ SP $(7,60)$ & $0,025+0,25$ & \\
\hline
\end{tabular}

$*$ preço considerando $100 \%$ do produto; ${ }^{* *}$ custo relativo ao AP comercial

Devido a maior concentração requerida e maior custo, as combinações com ácido lático se revelaram as mais caras. Mas as demais combinações apresentariam menor custo que o ácido propiônico utilizado industrialmente isoladamente. Embora o sorbato de potássio seja o mais caro a combinação com ácido propiônico poderia reduzir $24,63 \%$ do custo deste último sozinho. Destaca-se ainda a combinação do ácido acético e sorbato de potássio, que representaria uma economia de $70,19 \%$ para a indústria. Economia ainda mais vantajosa de $78,42 \%$ seria possível se aplicada a combinação de ácido acético e propiônico. O uso de compostos antimicrobianos em alimentos é resultante primeiramente de testes obtidos in vitro onde as condições do experimento são controladas. Há de considerar que estes valores são estimados e na escala industrial os ajustes são necessários, mas ainda assim, os valores são expressivos.

Para aplicação de ácidos orgânicos como agentes antifúngicos em rações, há de se considerar os constituintes da ração que poderão interferir para que não haja a mesma redução de $\mathrm{pH}$ obtida nos testes in vitro. $\mathrm{O}$ crescimento de bolores em alimentos depende de diversos fatores como a composição do produto, $\mathrm{pH}$, atividade de água, temperatura, umidade relativa, presença e concentração de conservantes, bem como tempo de armazenamento $^{[42]}$. Se armazenadas em locais com temperaturas e umidade relativa elevadas, a ração absorverá a água do ambiente, elevando sua atividade de água e umidade, 
proporcionando condições favoráveis a proliferação fúngica. O uso de conservantes com ação antifúngica, poderá servir então de barreira para o controle dessas condições de armazenamento.

\section{CONCLUSÃO}

Os ácidos acético e propiônico apresentaram sinergismo in vitro quando combinados com sorbato de potássio no controle de Aspergillusflavus. As determinações da CIM e do ICFI se destacam, pois revelaram menores concentrações necessárias para controle fúngico, com possiblidade de redução de custos quando comparados a dose de ácido propiônico comumente aplicado na indústria.

\section{REFERÊNCIAS}

[1] Hassan, R, El-Kadi, S, Sand, M. Effect Of Some Organic Acids On Some Fungal Growth And Their Toxins Production. International Journal of Advances in Biology.2015; 2: 1-11.

[2] Didwania, N, Joshi, M.Mycotoxins: a critical review on occurrence and significance.International Journal of Pharmacy and Pharmaceutical Sciences.2013; 5:1014-1019.

[3] Bullerman, LB, Bianchini, A. Stability of mycotoxins during food processing. International Journal of Food Microbiology. 2007;:119:.140-146.

[4] FDA- Food and Drug Administration. Select Committee on GRAS Substances (SCOGS) Opinion: Calcium Lactate, Lactic Acid. GRAS Substances (SCOGS) database.US Food and Drug Administration. 2015a.
[5] FDA- Food and Drug Administration. Select Committee on GRAS Substances (SCOGS) Opinion: Acetic Acid; Sodium Acetate; Sodium Diacetate. GRAS Substances (SCOGS) database.US Food and Drug Administration. 2015b.

[6] FDA- Food and Drug Administration. Select Committee on GRAS Substances (SCOGS) Opinion:Calcium propionate; Dilaurylthiodipropionate; Propionic acid; Sodium propionate; Thiodipropionic acid. GRAS Substances (SCOGS) database.US Food and Drug Administration. 2015c.

[7] FDA- Food and Drug Administration. Select Committee on GRAS Substances (SCOGS) Opinion:Calcium sorbate, Potassium sorbate, Sodium sorbate, Sorbic acid. GRAS Substances (SCOGS) database.US Food and Drug Administration. 2015d.

[8] Bellaver, C, Scheuermann, G. Aplicações dos ácidos orgânicos na produção de aves de corte. In: Conferência Avisul, 2005, Florianópolis. Anais. Florianópolis: [s.n.], 2005. $1-16$.

[9] Nobre, MO, Nascente, PS, Meireles, MC, Ferreiro, L. Drogas Antifúngicas para Pequenos e Grandes Animais. Ciência Rural.2002; 32: 175-184.

[10] FAO. Food and Agriculture Organization of the United NationsGood Practices for the Feed Industry - Implementing the Codex Alimentarius Code of Practice on Good Animal Feeding.n.9 Roma: FAO Animal Production and Health, 2010.

[11] Huang, Y, Wilson M, Chapman B, Hocking AD. Evaluation of the efficacy of four 
weak acids as antifungal preservatives in lowacid intermediate moisture model food systems.InternationalJournalofFoodMicrobiolo gy. 2010; 27: 33-36.

[12] Silva, N, Junqueira, VCA, Silveira, NFA, Taniwaki, MH, Santos, RFS, Gomes, RAR. Manual de Métodos de Análise Microbiológicas de Alimentos. São Paulo: Varela; 2010.

[13] Vicam. Aflatest instruction manual.Vicam, Watertown, MA: Vicam, 2002.

[14] IAL. Instituto Adolfo Lutz. Normas Analíticas do Instituto Adolfo Lutz: Métodos Químicos para Análise de Alimentos. 4. ed. São Paulo: Instituto Adolfo Lutz, 2008.

[15] Odds, F. C. Synergy, antagonism, and what the chequerboard puts between them. JournalofAntimicrobialChemotherapy. 2003; 52: $1-1$.

[16] Gierus, M, Sternowsky, S.Ração estruturada para maior produção animal novos desafios para o processamento de alimentos em fábricas de ração. 2013. Disponível em: $<$ https://pt.engormix.com/avicultura/artigos/ racao-estruturada-maior-producao-t38402.htm $>$.

[17] Maciorowski, K.G. Effects on poultry and livestock of feed contamination with bacteria and fungi.Animal Feed Science and Technology.2007; 133: 109-136.

[18] Jalili, M. A Review on Aflatoxins Reduction in Food.Iranian Journal of Health, Safety \& Environment.2015; 3 (1): 445-459.
[19] Milane, LV, Camilo, LJ, Schultz, R.A, Coradi, PC. Efeitos do Processamento para Redução de Micotoxinas na Produção de Ração. In: Conferência Brasileira de PósColheita 2014. Maringá. Anais. Maringá. 2014; 51:518-524.

[20] Brasil. Ministério da Saúde. Agência Nacional de Vigilância Sanitária. RDC no 7/11. Regulamento Técnico sobre limites máximos tolerados (LMT) para micotoxinas em alimentos. Diário Oficial da União, Brasília-DF, 18 fev. 2011. Seção 1, p.66-67.

[21] Comunidade Européia. Regulamento Da Comunidade Européia. Instrução Normativa 2003/100. Substâncias Indesejáveis nos Alimentos para Animais. DiárioOficial da UniãoEuropeia.31 out.2003, p.31-37.

[22] Coradi, PC, LacerdaFilho, AF, Chaves, JBP, Melo, E C. Effects of the feed processing in the reduction of the microbiological contamination on the final product. RevistaBrasileira de ProdutosAgroindustriais.2013; 15: 81-92.

[23] Cramer, JA, Prestegard, JH. NMR studies of $\mathrm{pH} /$ induced transport of carboxylic acids across phospholipids vesicle membranes. Biochemical and Biophysical Research Communications.1977; 75:295-301.

[24] O'Neil, M.J. (ed.). The Merck Index - An Encyclopedia of Chemicals, Drugs, and Biologicals. Cambridge, UK: Royal Society of Chemistry, 2013.

[25] Weast, R.C. (ed.). Handbook of Chemistry and Physics. 60th ed. Boca Raton, Florida: CRC Press Inc., 1979., p. B-114 
[26] Guynot, ME, Ramos, AJ, Sanchis, V, Marí, S. Study of benzoate, propionate, and sorbate salts as mould spoilage inhibitors on intermediate moisture bakery products of low $\mathrm{pH}$ (4.5-5.5). International Journal of Food Microbiology.2005; 101:161-168.

[27] Peláez, AM, Serna Cataño, CA, Quintero Yepes, EA, GambaVillarroel, RR, De Antoni, GL, Giannuzzi, L. Inhibitory activity of lactic and acetic acid on Aspergillusflavus growth for food preservation. Food Control.2012; 24: 177183.

[28] Higgins, C, Brinkhaus, F. Efficacy of several organic acids against mould. Journal of Applied Poultry Research.1999; 8:480-487.

[29] Muynck, C., Leroy AI, De Maeseneire S, Arnaut F, Soetaert W, Vandamme EJ. Potential of selected lactic acid bacteria to produce food compatible antifungal metabolites.Microbiologial Research.2004; 54: 339-346.

[30] Lind, H, Jonsson, H, Schnürer, J. Antifungal effect of dairy propionibacteria contribution of organic acids. International Journal of Food Microbiology.2005; 98: 157-65.

[31] Piper, PW. Yeast superoxide dismutase mutants reveal a pro-oxidant action of weak organic acid food preservatives.Free Radical Biology and Medicine. 1999; 27 (11): 12191227.

[32] Stratford, M, Anslow, PA. Evidence that sorbic acid does not inhibit yeast as a classic 'weak acid preservative'.Letters in Applied Microbiology.1998; 27: 203-206.
[33] Luther, MA, Cai, GZ, Lee, JC. Thermodynamics of dimer and tetramer formations in rabbit muscle phosphofructokinase. Biochemistry.1986; 25: 7931-7937.

[34] Legisa, M, Grdadolnik, SG. Influence of Dissolved Oxygen Concentration on Intracellular $\mathrm{pH}$ and Consequently on Growth Rate of Aspergillusniger.Food Technology and Biotechnology.2002; 40: 27-32.

[35] Lachowicz, KJ, Jones GP, Briggs DR, Bienvenu FE, Wan J, Wilcock A, Coventry MJ. The synergistic preservative effects of the essential oils of sweet basil (Ocimumbasilicum L.) against acid-tolerant food microflora.Letters in Applied Microbiology.1998; 26: 209-214.

[36] Nazer, AI, Kobilinsky, A, Tholozan, JL, Dubois-Brissonnet, F. Combinations of food antimicrobials at low levels to inhibit the growth of Salmonellasv. Typhimurium: a synergistic effect. Food Microbiology.2005; 22: 391-398.

[37] Periago, PM, Palop, A, Fernández, PS. Combined effect of nisin, carvacrol and thymol on the viability of Bacillus cereus heat-treated vegetative cells. Food Science and Technology. 2002; 7 (6): 487-492.

[38] York, GK, Vaughn, RH. Mechanisms in the inhibition of microorganisms by sorbic acid.Journal of Bacteriology.1964; 88:411-417.

[39] Hansch, C., Leo, A., D. Hoekman. Exploring QSAR - Hydrophobic, Electronic, and Steric Constants. Washington, DC: American Chemical Society. 1995; 4. 
[40] Brul, S, Coote, P. Preservative agents in foods Mode of action and microbial resistance mechanisms. International Journal of Food Microbiology.1999; 50:1-17.

[41] Molina, M, Giannuzzi, L. Combined effect of temperature and propionic acid concentration on the growth of Aspergillusparasiticus.Food Research International.1999; 32:677-688.

[42] Kosegarten, CE, Ramírez-Corona N, ManiLópez E, Palou E, López-Malo A. Description of Aspergillusflavus growth under the influence of different factors (water activity, incubation temperature, protein and fat concentration, $\mathrm{pH}$, and cinnamon essential oil concentration) by kinetic, probability of growth, and time-todetection models. International Journal of Food Microbiology.2017; 240: 115-123. 